\title{
MINERALOGIA DO DIQUE DE TONINHAS, UBATUBA, LITORAL NORTE DO ESTADO DE SÃO PAULO: FELDSPATOS
}

\author{
CELSO DE BARROS GOMES*
}

\begin{abstract}
Electron microprobe analyses for $\mathrm{Na}, \mathrm{K}$, and $\mathrm{Ca}$ are given for twenty feldspar crystals from the Mesozoic Toninhas dike which crops out near Ubatuba, along the north shoreline of the State of São Paulo. The rocks collected at different distances from the contact zone show very sharp textural, mineralogical, and chemical variations. At the central parts of the dike they are coarser grain-size and have a granophyric composition.

Chemical data for 456 grains indicate that about $70 \%$ of the analyzed plagioclases crystals have an andesitic composition. As given by 129 analyses, orthoclase with an Or content ranging from 66 to $99 \%$ seems to be the main potassic phase in the alkali feldspar group.

Some general considerations on the genesis of the Toninhas rocks are also taken by using chemical data of the feldspars.
\end{abstract}

INTRODUÇÃO Face às suas diversidades mineralógicas e texturais, as rochas do dique de 'l'oninhas, aflorando nas imediações da cidade de Ubatuba, litoral norte do Estado de São Paulo, vêm sendo minuciosamente pesquisadas quanto à sua história petrológica. Seu estudo petroquímico, contando com informações químicas (elementos principais e traços) de 22 amostras de rochas, foi levado a efeito recentemente por Gomes (no prelo) e Gomes e Berenholc (no prelo), enquanto se encontra em andamento um programa visando à determinação da composição química de seus minerais principais: feldspatos, piroxênios e opacos. $O$ presente trabalho reúne as informações coligidas para o grupo dos feldspatos e que foram objeto de ligeira apreciação por Gomes (1973).

$\mathrm{O}$ dique de Toninhas, encaixado em rochas pré-cambrianas de natureza gnáissica-charnockítica, possui forma vertical e largura de aproximadamente 90 metros. Antes dos trabalhos, que culminaram com o alargamento da rodovia Caraguatatuba - Ubatuba, um de seus contatos era visível, além de permitir a amostragem progressiva dessa região até as porções centrais do corpo, estas cobertas inteiramente por ocasião da maré alta. À exceção de uma breve citação em Damasceno (1966) e dos dados geocronológicos constantes do trabalho de Amaral e outros (1966), atribuindo-lhes idade cretácica, nada mais existe na literatura sobre tais rochas a despeito do fato de as mesmas terem despertado grande interesse junto a diversos pesquisadores que visitaram a ocorrência.

Feldspatos (plagioclásio e feldspato alcalino) e quartzo constituem os minerais siálicos mais importantes dessas rochas, enquanto os ferromagnesianos têm nos piroxênios (augita e pigeonita) seus principais representantes. Produtos de alteração incluem anfibólio e biotita, encontrados principalmente ao redor dos cristais de piroxênio ou mesmo ao longo de suas linhas de clivagem. Opacos e apatita ocorrem em pequena concentração; titanita é rara e sericita, clorita e epídoto correspondem aos minerais secundários mais comuns.

Dados petrográficos demonstram que as rochas do dique exibem grande heterogeneidade quanto à textura e a mineralogia. Junto à região de contato, a granulação é extremamente fina (tendo sido inclusive reconhecida uma pequena faixa vítrea de 3 centímetros em média de largura), aumentando progressivamente em direção ao centro do corpo. Petrograficamente, a rocha poderia ser classificada como um basalto, passando no entanto

* Departamento de Mineralogia e Petrologia, Instituto de Geociências, Universidade de São Paulo. Caixa Postal 20899, São Paulo, Brasil 
a diabásio à medida que se afasta do contato. A coloração é escura e a textura variável de ofitica a subofitica. Nas partes centrais do dique, as rochas apresentam granulação grossa, textura nitidamente granular e composição marcadamente granofírica. Em adição a estas feições, as rochas ostentam coloração dominantemente rosada e uma estrutura fortemente bandeada, refletida sobretudo na concentração seletiva dos ferromagnesianos, paralela à direção do contato. Mineralogicamente merecem menção as variações devidas ao aumento das concentrações de quartzo, feldspato alcalino e sericita (muscovita) junto às rochas do centro do corpo em detrimento sobretudo de plagioclásio e piroxênio.

O plagioclásio, invariavelmente de forma tabular, acha-se geminado segundo albita-Carlsbad, aparecendo subordinadamente à lei do periclínio. Zoneamento, quando presente do tipo normal, é pouco conspícuo, enquanto sericitização constitui o processo de alteração mais freqüente. $O$ feldspato alcalino é sempre xenomórfico e ocupa, juntamente com o quartzo, os interstícios dos demais minerais da rocha. $\mathrm{Na}$ maioria das vezes, acha-se associado intimamente ao quartzo na forma de intercrescimento gráfico, contudo, em algumas amostras, parece ter-se formado na periferia dos cristais de plagioclásio.

PARTE ANALITICA A composição química parcial dos feldspatos foi determinada com o auxílio da técnica da microssonda eletrônica e processou-se em duas' etapas distintas. $\mathrm{Na}$ primeira delas, contou-se com o instrumento MAC-400S, da Materials Analysis Corporation, tendo sido o trabalho analítico executado no laboratório do Departamento de Geologia da Universidade da Geórgia, Athens, Estados Unidos da América. Este programa envolveu principalmente a análise do plagioclásio. A segunda fase foi realizada no laboratório do Instituto de Geociências da Universidade de São Paulo e o aparelho empregado um EMX-SM, da Applied Research Laboratories. Consistiu sobretudo da análise do feldspato alcalino, usando-se para tal as mesmas seções empregadas no programa anterior.

As condições de instrumentação usadas em ambos os programas analíticos foram as que se seguem: potencial de aceleração $15 \mathrm{kV}$, corrente de amostra 0,03-0,09 $\AA$, tempo de integração nos contadores $20^{\prime \prime}$ e diâmetro do feixe eletrônico 1 a $20 \mu$. As condições de análise foram ajustadas para eliminar-se qualquer perda de $\mathrm{K}$ e $\mathrm{Na}$ por volatização. Como padrőes foram utılizados apenas minerais naturais, a saber: albita (Tiburon), bytownita (Grystal Bay) e ortoclásio, respectivamente, para sódio, cálcio e potássio. Os resultados obtidos foram corrigidos para desvio e radiação de fundo. Cerca de vinte rochas foram analisadas, variando, no entanto, o total de determinações para cada amostra. Assim, para o plagioclásio, um número maior de cristais foi analisado junto às amostras da regiåo de contato, o inverso ocorrendo com o feldspato alcalino. No total, foram analisados 456 grãos de plagioclásio e 129 de feldspato alcalino. A precisão dos dados é estimada entre $1 \%$ e $2 \%$.

Discussão dos RESUltados Os dados químicos de 456 cristais de plagioclásio de amostras de rochas coletadas a diferentes distâncias da região do contato do dique (valores expressos em unidades de metro), como indicado pela porcentagem em peso dos componentes, albita, ortoclásio e anortita, acham-se reunidos nos diagramas ternários das Figs. 1 e 2. A composição média para cada amostra, acompanhada dos valores correspondentes à medida do desvio, constam da Tab. I. Por sua vez, a Fig. 3 mostra a relação existente entre essa composição e o campo de variação do teor de anortita para cada amostra com a sua posição relativa dentro do corpo.

$\mathrm{O}$ exame das Figs. 1 e 2 permite prontamente concluir que o componente potássico não tem partićipação importante na composição do plagioclásio, bem como que a sua concentração aumenta ligeiramente nas amostras mais distantes da borda do dique. Nestas 


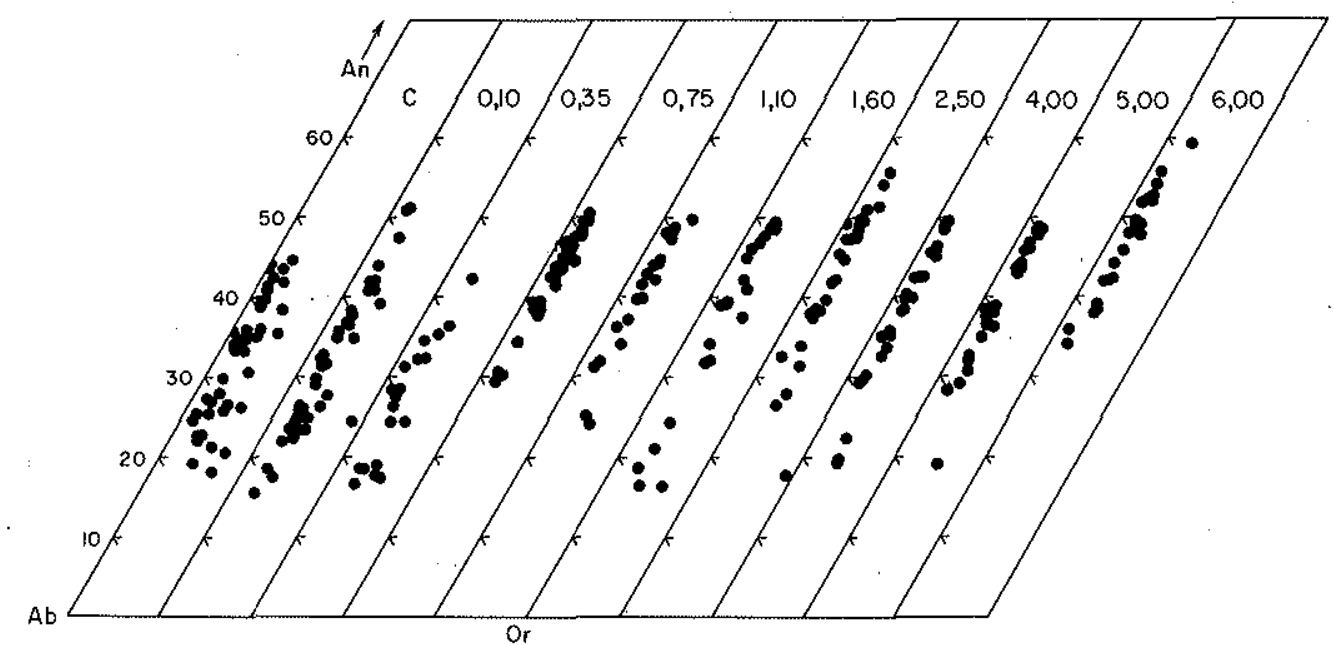

Figura 1 - Variaçães químicas em plagioclásios expressas em função da porcentagem em peso dos componentes albita, ortoclásio e anortita $(\mathrm{C}=$ amostra da zona do contato; demais valores indicam diferentes distâncias a partir dessa região)

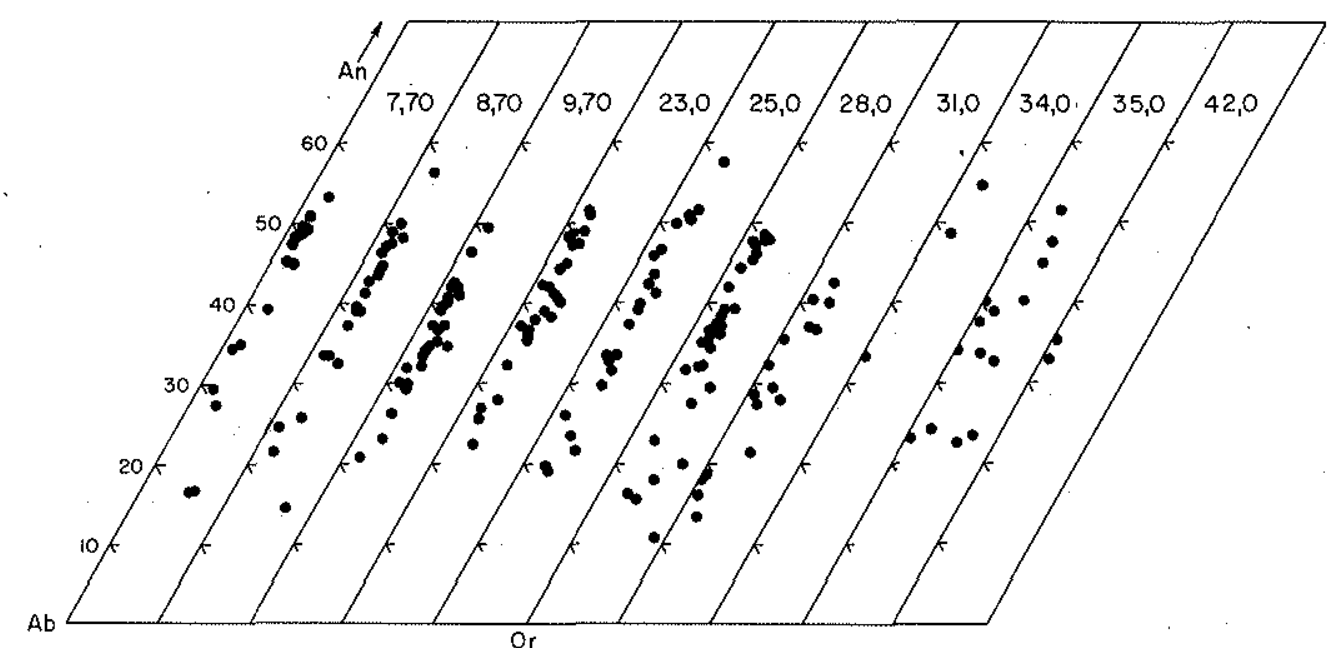

Figura 2 - Variações químicas em plagioclásios expressas em função da porcentagem em peso dos componentes albita, ortoclásio e anortita $(\mathrm{C}=$ amostra da zona do contato; demais valores indicam diferentes distâncias a partir dessa regiaxo)

últimas rochas, os pontos em geral apresentam maior dispersão ao contrário do ocorrido naquelas mais próximas da margem, onde se configura perfeitamente uma disposição linear dos cristais e paralela ao lado sódico-ćĺcico do triângulo. $\mathrm{O}$ caráter diferenciado das rochas do dique de Toninhas acha-se evidenciado pela composição do plagioclásio, de natureza andesínica para $70 \%$ das amostras analisadas, como se depreende do histograma da Fig. 4, Chama particularmente atenção a falta de homogeneidade química dentro de cada amostra, com variações na série albita-anortita alcançando valores de até $40 \%$.

Aparentemente, como sugerido pelas Figs. 1, 2 e 3, os plagioclásios das amostras do contato são mais sódicos, mantendo-se, no entanto, a concentração em cálcio, uma vez 
Tabela I - Composição química média de plagioclásios

\begin{tabular}{ccccc}
\hline & $\mathrm{Ab}$ & An & Or & N. $^{\circ}$ amostras \\
\hline $\mathrm{C}$ & $64,6 \pm 5,8$ & $32,7 \pm 6,3$ & $2,6 \pm 1,0$ & 43 \\
0,10 & $65,6 \pm 7,1$ & $31,7 \pm 7,4$ & $2,7 \pm 0,8$ & 40 \\
0,35 & $70,6 \pm 6,1$ & $26,9 \pm 6,3$ & $3,0 \pm 0,8$ & 19 \\
0,75 & $55,3 \pm 4,1$ & $42,9 \pm 4,1$ & $1,8 \pm 0,2$ & 35 \\
1,10 & $56,8 \pm 5,8$ & $40,7 \pm 6,2$ & $2,5 \pm 0,6$ & 21 \\
1,60 & $59,9 \pm 7,6$ & $37,2 \pm 8,2$ & $2,8 \pm 0,8$ & 20 \\
2,50 & $55,1 \pm 6,8$ & $42,3 \pm 7,5$ & $2,6 \pm 1,0$ & 27 \\
4,00 & $60,1 \pm 6,5$ & $37,7 \pm 7,1$ & $2,1 \pm 0,6$ & 26 \\
5,00 & $57,8 \pm 5,8$ & $40,4 \pm 5,8$ & $1,9 \pm 0,4$ & 23 \\
6,00 & $52,3 \pm 5,0$ & $45,4 \pm 5,6$ & $2,3 \pm 0,4$ & 23 \\
7,70 & $54,6 \pm 6,9$ & $43,6 \pm 7,0$ & $2,0 \pm 0,4$ & 23 \\
8,70 & $58,5 \pm 7,6$ & $39,2 \pm 8,0$ & $2,3 \pm 0,6$ & 26 \\
9,70 & $62,2 \pm 5,1$ & $35,7 \pm 5,3$ & $2,2 \pm 0,6$ & 26 \\
23,0 & $58,2 \pm 6,2$ & $39,3 \pm 6,5$ & $2,4 \pm 0,6$ & 23 \\
25,0 & $59,5 \pm 9,2$ & $37,5 \pm 9,3$ & $3,1 \pm 0,6$ & 31 \\
28,0 & $62,0 \pm 7,2$ & $34,8 \pm 8,1$ & $3,2 \pm 1,1$ & 15 \\
31,0 & $69,0 \pm 8,4$ & $29,0 \pm 8,0$ & $2,2 \pm 1,1$ & 3 \\
34,0 & $52,4 \pm 9,1$ & $45,6 \pm 8,1$ & $2,0 \pm 0,9$ & 14 \\
35,0 & $61,4 \pm 7,3$ & $35,5 \pm 7,6$ & $3,0 \pm 1,3$ & 2 \\
42,0 & $64,8 \pm 1,1$ & $34,8 \pm 1,5$ & $0,4 \pm 0,3$ & \\
\hline
\end{tabular}

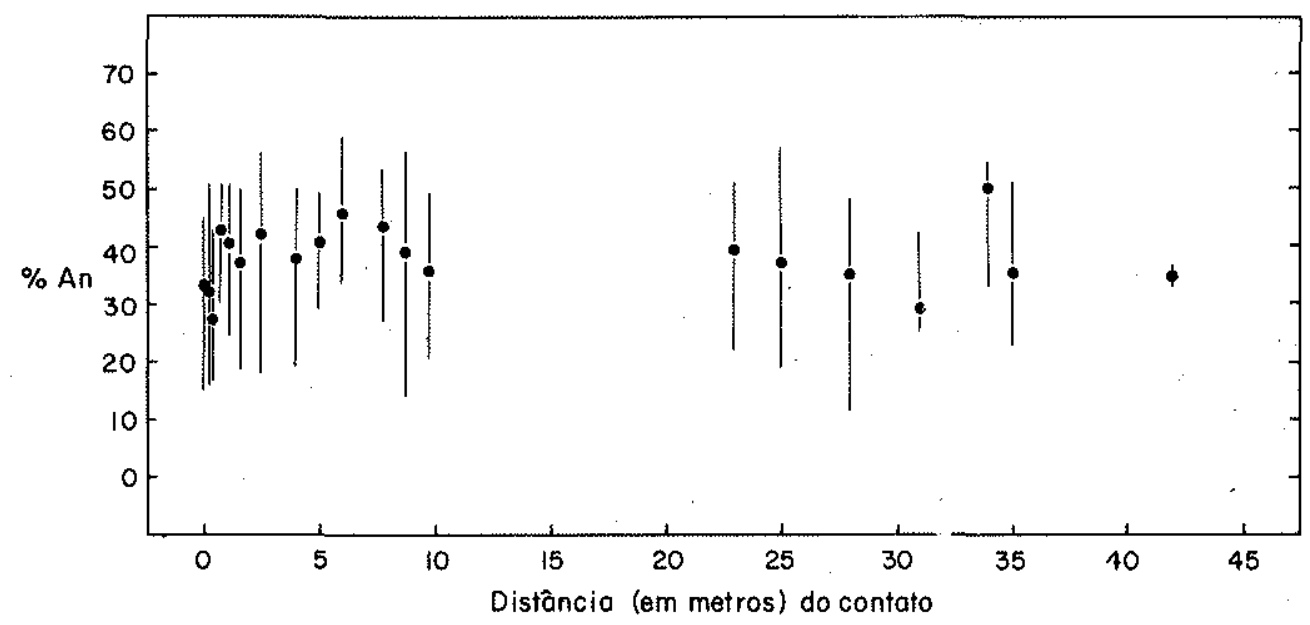

Figura 3 - Gráfico relacionando o campo de variação do teor em anortita dos plagioclásios, seu valor médio, com a posição de coleta da amostra dentro do dique

excluídas as amostras distantes mais de 30 metros dessa zona onde as informações disw poníveis são insuficientes para uma perfeita caracterização, mais ou menos constante nas demais porções do corpo. Poder-se-ia tentar explicar este fato, de conformidade com Evans e Moore (1968), pela marcante cristalização da augita, antes de iniciada a do plagioclásio, nas amostras do contato, acarretando assim um esgotamento do liquido magmático em cálcio. 
Figura 4 - Histograma de composição para os cristais de plagioclásio das rochas de Toninhas

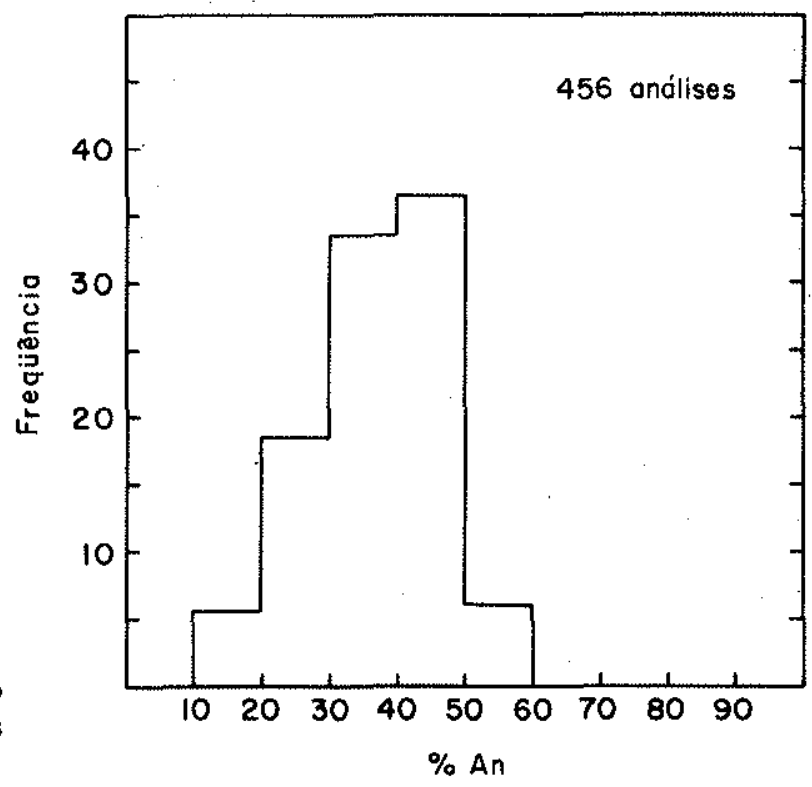

Os dados relativos a 129 grãos de feldspato alcalino, aparentemente guardando a composição de ortoclásio, pertencentes às mesmas amostras referidas atrás estão também representados em gráficos ternários tendo albita, ortoclásio e anortita como vértices do triângulo (Figs. 5 e 6). A composição química média desses minerais e os valores referentes ao desvio médio acham-se reunidos na Tab. II. Uma visão conjunta dos dados químicos coligidos para ambos os grupos de feldspatos é fornecida na Fig. 7.

A despeito do menor número de análises para os feldspatos alcalinos e da maior dispersão dos pontos em algumas amostras, observa-se que os mesmos são mais enriquecidos em potássio nas variedades petrográficas das porções periféricas e centrais da intrusão. Se por um lado a diminuição progressiva na concentração em potássio desses minerais

Figura 5 - Variaçðes químicas em feldspatos alcalinos expressas em função da porcentagem em peso dos componentes albita, ortoclásio $e$ anortita $(\mathrm{C}=$ amostra da zona do contato; demais valores indicam diferentes distâncias a partir dessa região)

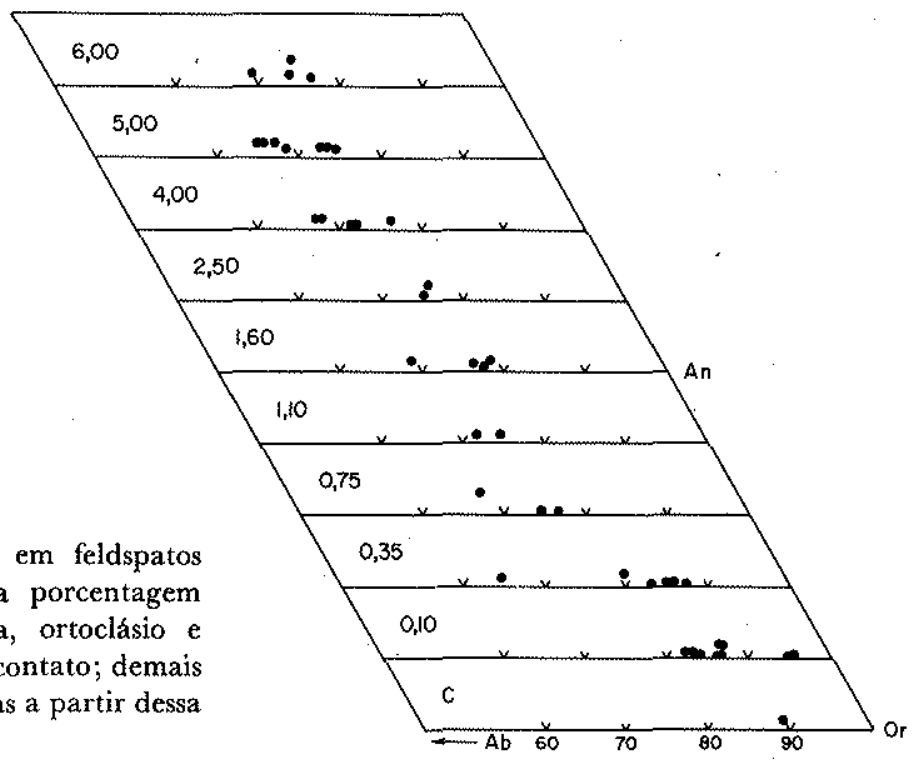




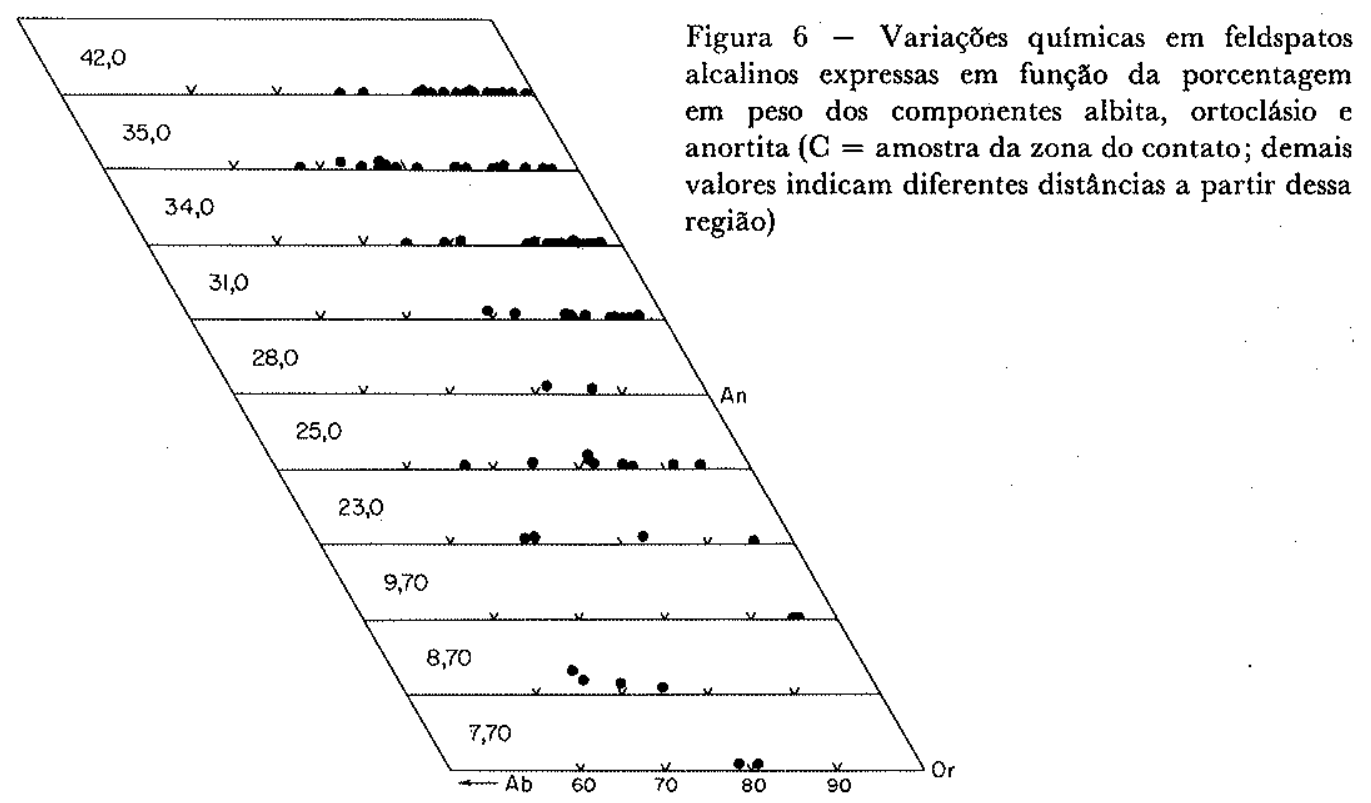

Tabela II - Composição química média de feldspatos alcalinos

\begin{tabular}{crllc}
\hline & Ab & An & Or & N. $^{\circ}$ amostras \\
\hline C & \multicolumn{1}{c}{9,0} & 1,8 & 89,2 & 1 \\
0,10 & $11,8 \pm 3,5$ & $1,3 \pm 0,5$ & $86,8 \pm 3,2$ & 9 \\
0,35 & $17,4 \pm 5,3$ & $1,1 \pm 0,5$ & $81,5 \pm 5,7$ & 6 \\
0,75 & $25,0 \pm 2,1$ & $1,5 \pm 1,1$ & $73,5 \pm 3,2$ & 3 \\
1,10 & $24,7 \pm 1,4$ & $1,5 \pm 0,1$ & $73,9 \pm 1,5$ & 2 \\
1,60 & $22,6 \pm 4,7$ & $1,5 \pm 0,3$ & $75,9 \pm 3,3$ & 4 \\
2,50 & $22,2 \pm 1,4$ & $1,7 \pm 0,7$ & $76,1 \pm 0,7$ & 2 \\
4,00 & $27,1 \pm 2,5$ & $1,3 \pm 0,3$ & $71,6 \pm 2,5$ & 5 \\
5,00 & $28,1 \pm 3,1$ & $1,5 \pm 0,3$ & $70,2 \pm 3,3$ & 7 \\
6,00 & $24,1 \pm 2,2$ & $1,8 \pm 0,7$ & $76,6 \pm 2,5$ & 4 \\
7,70 & $19,3 \pm 1,1$ & $0,9 \pm 0,1$ & $79,9 \pm 1,2$ & 2 \\
8,70 & $28,6 \pm 2,8$ & $2,1 \pm 0,8$ & $69,4 \pm 3,4$ & 4 \\
9,70 & $4,8 \pm 0,1$ & & $95,2 \pm 0,1$ & 2 \\
23,0 & $19,7 \pm 9,4$ & $0,8 \pm 0,3$ & $79,5 \pm 9,7$ & 4 \\
25,0 & $16,4 \pm 5,4$ & $0,8 \pm 0,4$ & $82,8 \pm 5,8$ & 9 \\
28,0 & $14,5 \pm 2,3$ & $1,0 \pm 0,3$ & $84,5 \pm 2,6$ & 2 \\
31,0 & $8,1 \pm 4,0$ & $0,3 \pm 0,3$ & $91,6 \pm 4,3$ & 12 \\
34,0 & $7,3 \pm 3,8$ & $0,2 \pm 0,1$ & $92,5 \pm 3,5$ & 32 \\
35,0 & $16,4 \pm 7,6$ & $0,3 \pm 0,2$ & $83,3 \pm 7,8$ & 15 \\
42,0 & $9,2 \pm 5,1$ & $0,1 \pm 0,1$ & $90,7 \pm 5,1$ & 21 \\
\hline
\end{tabular}

a partir do contato, que ocorre certamente até 23 metros, é facilmente entendida, uma vez admitida a existência de processos de diferenciação magmática dentro do dique, torna-se no entanto dificil explicar o enriquecimento posterior ocorrido nas quatro amostras distantes mais de 30 metros da borda, que supostamente deveriam ser mais ricas em sódio 
Figura 7 - Variaçðes químicas em plagioclásios e feldspatos das rochas de Toninhas como indicado pela porcentagem em peso dos componentes albita, ortoclásio e anortita. Trata-se em realidade da apresentação conjunta dos dados fornecidos nas Figs. 1, 2,5 e 6

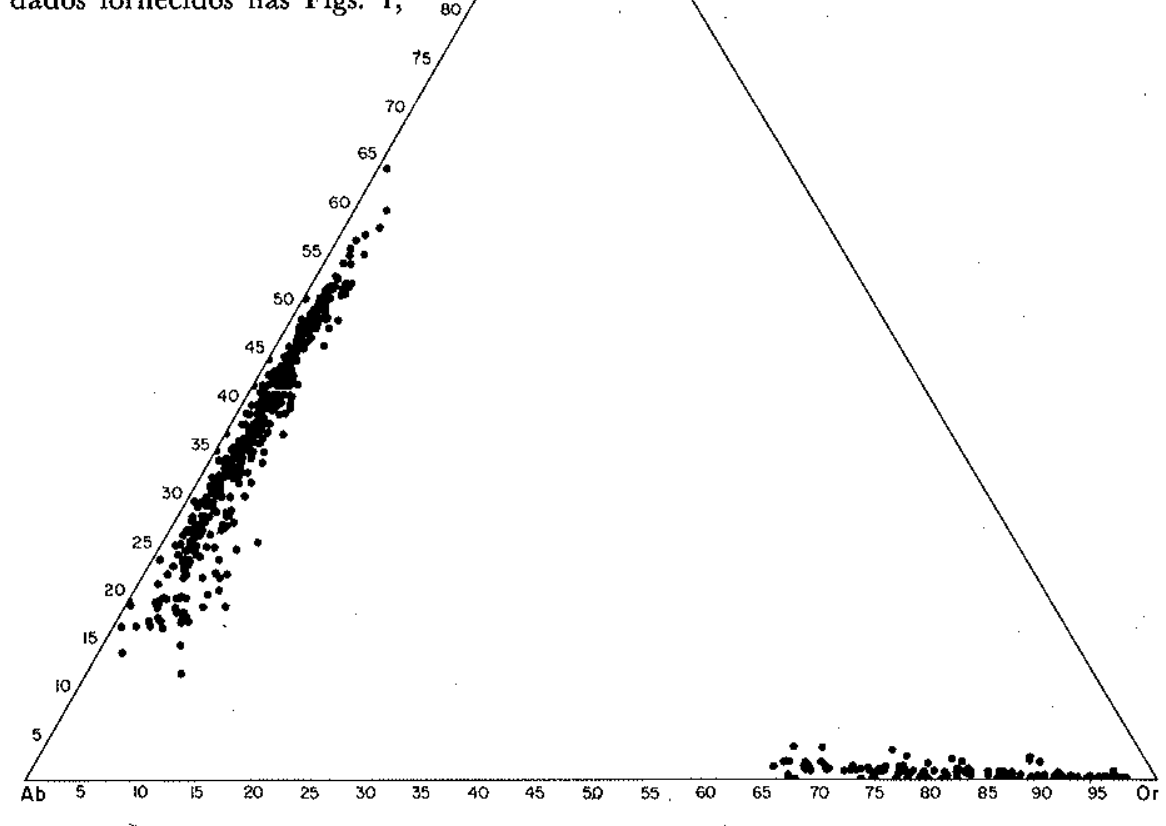

de conformidade com o diagrama de equilíbrio do sistema ternário $\mathrm{NaAlSi}_{3} \mathrm{O}_{8}-\mathrm{KAlSi}_{3} \mathrm{O}_{8}$ - $\mathrm{CaAISi}_{2} \mathrm{O}_{8}$ de Tuttle e Bowen (1958), assumindo-se apenas aquele mecanismo genético.

Este fato, aliado às evidências químicas contidas em Gomes e Berenholc (no prelo), que apontam as quatro últimas amostras como tendo sido originadas a partir de um liquido magmático fortemente diferenciado, parece indicativo de que diversos mecanismos intervieram na formação das rochas do dique. Conquanto os dados disponíveis sejam insuficientes para esclarecer devidamente toda sua história petrologica, poder-se-ia supor que, em adição à clássica diferenciação magmática, tais rochas foram também submetidas a outros processos genéticos, como transferência de gases, intrusão múltipla ou mesmo uma combinação dos dois últimos, que teriam sido os agentes responsáveis pelas condiçбes químicas anômalas que nortearam a cristalização dos feldspatos. Dessa forma, os feldspatos alcalinos das quatro amostras mais centrais do corpo representariam um produto de uma fase de cristalização posterior, geocronologicamente mais nova, marcada sobretudo pela presença de soluções fortemente enriquecidas em álcalis e agentes voláteis.

Agradecimentos $\mathrm{O}$ autor agradece ao Conselho Nacional de Pesquisas (Proc. 5876/70; T.C. 12.654) a concessão do auxílio financeiro que possibilitou a realização desta pesquisa. Agradecimentos são também devidos ao Dr. J. V. Valarelli pela revisão do manuscrito.

\section{BIBLIOGRAFIA}

AMARAL, G., GORDANI, U. G., KAWASHITA, K. e REYNOLDS, J. H. - 1966 - Potassium Argon ages of basaltic rocks from Southern Brazil. Geochim. Cosmochim. Acta, 30 (2): 159-189 
DAMASCENO, E. C. - 1966 - Estudo preliminar dos diques de rochas básicas e ultrabásicas da regiåo de Ubatuba, Estado de São Paulo. An. Acad. Bras. Ci., 38 (2): 293-304

EVANS, B. W. e MOORE, J. G. - 1968 - Mineralogy as a Fuction of Depth in the Prehistoric Makaopuhi Tholeiitic Lava Lake, Hawaii, Contr. Mineral. and Petrol., 17: 85-115

GOMES, G. B. - 1973 - Comportamento dos feldspatos do dique de diabásio de Toninhas, Ubatuba, S.P. XXVII Congr. Bras. Geol., Bol. 1: 75

GOMES, G. B. - no prelo - Estudo petrológico do dique de Toninhas, Ubatuba, Litoral Norte do Estado de São Paulo. An. Acad. Bras. Ci.

GOMES, G. B. e BERENHOLC, M. - no prelo - Some geochemical features of the Toninhas dike, Ubatuba, State of São Paulo, Brazil. An. II Congr. Latino-americano Geol. Caracas

TUTTLE; O.F. e BOWEN, N. L. - 1958 - Origin of granite in the light of experimental studies in the system $\mathrm{NaAlSi}_{3} \mathrm{O}_{4}-\mathrm{KAlSi}_{3} \mathrm{O}_{8}-\mathrm{SiO}_{2}-\mathrm{H}_{2} \mathrm{O}$. Mem. Geol. Soc. Amer., 74 